\title{
New lives given by cell death: macrophage differentiation following their encounter with apoptotic leukocytes during the resolution of inflammation
}

\author{
Amiram Ariel ${ }^{1}$ * and Charles N. Serhan ${ }^{2}$ \\ 1 Department of Biology, University of Haifa, Haifa, Israel \\ 2 Department of Anesthesiology, Center for Experimental Therapeutics and Reperfusion Injury, Perioperative and Pain Medicine, Brigham and Women's Hospital, \\ Harvard Medical School, Boston, MA, USA
}

\section{Edited by:}

Jerrold S. Levine, University of Illinois at Chicago, USA

\section{Reviewed by:}

Pablo Pelegrin, Hospital Universitario Virgen Arrixaca, Spain

Patrizia Rovere Querini, Vita-Salute

University, Italy

\section{${ }^{*}$ Correspondence}

Amiram Ariel, Department of Biology, University of Haifa, Haifa 31905, Israel.

e-mail:amiram@research.haifa.ac.il
Monocytes that migrate into tissues during inflammatory episodes and differentiate to macrophages were previously classified as classically (M1) or alternatively (M2) activated macrophages, based on their exposure to different fate-determining mediators. These macrophage subsets display distinct molecular markers and differential functions. At the same time, studies from recent years found that the encounter of apoptotic leukocytes with macrophages leads to the clearance of this cellular "debris" by the macrophages, while concomitantly reprogramming/immune-silencing the macrophages. While some of the features of M2 differentiation, such as arginase-1 (murine) and 15-lipoxygenases (human and murine) expression, were also displayed by macrophages following the engulfment of apoptotic cells, it was not clear whether apoptotic cells can be regarded as an M2-like differentiating signal. In this manuscript we review the recent information regarding the impact of apoptotic cells on macrophage phenotype changes in molecular terms. We will focus on recent evidence for the in vivo existence of distinct pro-resolving macrophages and the role of apoptotic cells, specialized lipid mediators, and glucocorticoids in their generation. Consequently, we will suggest that these pro-resolving CD11 bow macrophages have metamorphed from M2-like macrophages, and modulated their protein profile to accommodate the changes in their function.

\section{Keywords: resolution of inflammation, macrophage differentiation, efferocytosis, pro-resolving lipid mediators}

\section{INTRODUCTION}

Macrophages are highly plastic monocyte-derived cells that acquire different molecular and functional phenotypes following exposure to different bioactive molecules and environments. The early studies on the interactions of macrophages and lymphocytes in battling bacterial infections revealed the T helper type 1 (Th1) secreted cytokine IFN $\gamma$ to be involved in the classical activation of macrophages (Nathan et al., 1983). However, seminal studies by the groups of Gordon and Mantovani have extensively characterized additional macrophage subtypes activated in alternative manners (reviewed in Mantovani et al., 2004; Martinez et al., 2009). Since the major polarizing cytokines initially found to be involved in classical and alternative activation were derived from Th1 (IFN $\gamma$ ) and Th2 (IL-4 and IL-13) lymphocytes these activated macrophages were named M1 and M2, respectively. Later studies revealed that in addition to IL-4, alternative activation can also be induced by immune complexes and glucocorticoids (Martinez et al., 2008), and accordingly the subdivision of alternatively activated macrophages to M2a-c was instilled. M1 macrophages are important inducers and effectors in the Th1 response. They are instrumental in immune responses against intracellular microbes and tumors (Mantovani et al., 2005). M2 macrophages are more heterogeneous, but generally play a role in Th2 responses, such as killing and encapsulation of extracellular parasites, resolving type 1 inflammation, and promoting tissue repair and remodeling. M2 macrophages are also playing a role in immune regulation and promote tumor progression (Mantovani et al., 2005; Martinez et al., 2009). M1 and M2 macrophages are not only distinct in function, but also express different receptors and enzymes required for their activities. M1 macrophages express high levels of inflammatory cytokines (IL-12, IL-23, TNF $\alpha, \mathrm{IL}-1 \beta$, and IL-6) and chemokines (CXCL9, 10, and 11, CCL2, 3, 4, and 5, and CXCL2), as well as enzymes involved in the generation of reactive oxygen species (ROS) and nitric oxide (NO; Mantovani et al., 2005). M2 macrophages express lower levels of inflammatory mediators, but high levels of IL-10, scavenger, mannose, and galactose receptors. Importantly, in mice, M2 express the enzyme arginase- 1 that intercepts the NO generation pathway [though inducible NO synthase (iNOS)] to generate ornithine and polyamines that are instrumental in tissue repair and fibrosis (Hesse et al., 2001). Hence, the expression of iNOS and arginase- 1 are major markers deciphering M1 and M2 macrophages. Additional markers of M2, such as YM1 and FIZZ1, were later identified in mouse macrophages (Raes et al., 2002, 2005).

Macrophages also undergo dramatic molecular and functional changes upon encounter, interaction with, and uptake of apoptotic cells (efferocytosis) during the resolution of inflammation. In this article we will highlight some of the similarities between M2 
differentiation and transcriptional events activated by early efferocytosis. In addition, we will discuss recent results that support the notion that efferocytosis can eventually transform macrophages to another phenotype that is postulated to limit tissue repair/fibrosis and promote macrophage regulatory properties at remote sites. In this regard, it is important to note the early studies that indicated "non-phlogistic" activation of monocytes by the pro-resolving lipid mediators lipoxins. This bioactivity of lipoxins resulted in increased adhesion and migration of human monocytes (Maddox and Serhan, 1996; Maddox et al., 1997, 1998) hence prompting the notion that resolution-driven monocyte/macrophage activation promotes tissue repair and wound healing.

\section{EFFEROCYTOSIS AS AN ALTERNATIVE MODE OF MACROPHAGE ACTIVATION}

The recognition, engulfment, and responsiveness to apoptotic cells are cardinal properties of resident and inflammatory macrophages and play a role in processes, such as tissue morphogenesis and homeostasis, embryonic development, hematopoiesis, immunity, and the resolution of inflammation (Savill et al., 2002; Erwig and Henson, 2007; Ravichandran and Lorenz, 2007). The recognition and uptake of apoptotic cells by macrophages through "eat me" signals (and the absence of "do not eat me" signals) expressed on their surface and their cognate receptors have been extensively studied and reviewed (Ravichandran, 2011). However, apoptotic cells also transduce signals to the engulfing macrophages that result in significant molecular and functional adjustments that address physiological needs consequent to the identified cell death. During the resolution of inflammation, macrophages engulf apoptotic cells and consequently, apoptotic cell recognition evokes distinct signaling events (Patel et al., 2006) that block the release of pro-inflammatory mediators from macrophages. This release is activated by bacterial moieties, and its blockage, which is termed immune-silencing (Voll et al., 1997; Fadok et al., 1998; Kim et al., 2004), is accompanied by the production of TGF $\beta$ and IL-10 (Byrne and Reen, 2002; Huynh et al., 2002; Mitchell et al., 2002), cytokines that can promote resolution and wound repair. The engulfment of apoptotic leukocytes by macrophages also leads to inhibition of iNOS expression and stimulates the expression of arginase- 1 in the RAW 264 macrophage cell line (Freire-De-Lima et al., 2006) thereby preventing reactive NO production. In addition, the production of angiogenic growth factors (Golpon et al., 2004) by macrophages is consequent to the uptake of apoptotic cells. Elucidation of the signaling pathways activated by efferocytosis revealed significant roles for nuclear transcriptional regulators, such as peroxisome proliferator activated receptor (PPAR)- $\gamma$ (Freire-De-Lima et al., 2006; Johann et al., 2006) and $-\delta$ (Mukundan et al., 2009) as well as the liver $\mathrm{X}$ receptor (LXR; A-Gonzalez et al., 2009) in promoting anti-inflammatory properties.

It is important to note that while macrophages engulf tissueinfiltrating apoptotic PMN during the resolution of inflammation, different experimental models used different sources of apoptotic cells, including Jurkat $\mathrm{T}$ cells, mouse thymocytes, or human peripheral blood neutrophils. All types of apoptotic cells express phosphatidylserine on the outer leaflet of their cytoplasmic membrane, and this is apparently the major signaling module used by these cells to communicate their mortal status with phagocytic cells (Ravichandran, 2011). Nevertheless, it is conceivable that other molecules ("eat me signals") are expressed on apoptotic cells of different sources to give a more detailed "report" as to the consequences of their demise. Thus, the interpretation of the results obtained following incubations of macrophages with apoptotic cells of different sources should be evaluated carefully depending on the source of apoptotic cells used.

The prototypic Th2 cytokines IL-4, IL-13, and IL-10, as well as immune responses to parasites were found to promote many of the outcomes of efferocytosis in macrophages. These cytokines are well appreciated antagonists of the M1 response and macrophage pro-inflammatory properties (Martinez et al., 2009) while IL-4 and IL-13 can also promote fibrosis through TGF $\beta$ production (Fichtner-Feigl et al., 2006; Wynn, 2008). IL-13 was also found to promote vascular endothelial growth factor production during lung injury (Corne et al., 2000). Importantly, IL-4 and IL-13 also activate PPAR- $\gamma$ (Huang et al., 1999; Berry et al., 2007) and PPAR- $\delta$ (Kang et al., 2008) to promote monocyte/macrophage alternative activation. LXR was recently found to synergize with IL-4 in the induction of arginase-1 expression and promotion of an M2 phenotype in regressive atherosclerotic lesions (Pourcet et al., 2011). Thus, efferocytosis induces phenotypic and molecular switches and activates signaling pathways in macrophages that resemble M2 polarization. Moreover, M2 polarization promotes efferocytosis through induction of different molecular modules, whereas M1 macrophages exert reduced uptake of apoptotic cells. Along these lines, recent studies also found that efferocytosis is a self-promoting process, and that M2 pathways play key roles in mediating this feature of macrophage function. These aspects of efferocytosis are covered by Korns et al. (2011) in this research topic and will not be elaborated on here. Nevertheless, while macrophages are paradoxically involved in both the generation of fibrosis and its resolution (Wynn and Barron, 2010) and efferocytosis and M2 polarization generate a positive feedback loop during resolution of inflammation, it is much less clear what are the events and mediators that stop M2 differentiation and tissue repair/remodeling short of excessive, fibrotic outcomes. Such events and mediators are inevitably required to complete the resolution of inflammation and restore homeostasis rather than end every infection with a debilitating scar.

\section{5-LIPOXYGENASE AND ITS PRODUCTS}

A major enzymatic pathway that mediates key events in the resolution of inflammation involves the expression and activation of 12/15-lipoxygenase (LO) in mice and 15-LO1 in humans. 15-LO expression and activity are upregulated by IL- 4 and IL-13 in murine and human monocytes, macrophages, and peripheral blood mononuclear cells (Levy et al., 1993; Nassar et al., 1994; Heydeck et al., 1998; Huang et al., 1999; Ariel et al., 2005). This upregulation leads to the production of 15-LO products from eicosatetraenoic and docosahexaenoic acids (ETA and DHA, respectively), such as 15-hydroxyeicosatetraenoic acid (15-HETE), lipoxin (LX) $\mathrm{A}_{4}$ and $\mathrm{B}_{4}(5 S, 6 S, 15 S$-trihydroxy-7E,9E,11Z,13E-EPA, and $5 S, 14 R, 15 S$ trihydroxy-6E,8Z,10E,12E-EPA, respectively), 17S-hydroxy-DHA (17S-hydroxy-4Z,7Z,10Z,13Z,15E,19Z-DHA), and protectin D1 
(10R,17S-dihydroxy-4Z,7Z,11E,13E,15Z,19Z-DHA). Macrophage expression of 12/15-LO was found to promote the production of resolvin (Rv) D1 (7S,8R,17S-trihydroxy-4Z,9E,11E,13Z,15E,19ZDHA) and maresin 1 (7,14-dihydroxy-4Z,8,10,12,16Z,19Z-DHA), in addition to $\mathrm{LXA}_{4}$ and PD1 (Merched et al., 2008; Serhan et al., 2009). The expression of 12/15-LO was also found to be upregulated in mouse macrophages following their incubation with apoptotic cells (Freire-De-Lima et al., 2006; Schif-Zuck et al., 2011) and resulted in the production of 15-HETE and $\mathrm{LXA}_{4}$ (Freire-De-Lima et al., 2006). Macrophages from chronic granulomatous disease (CGD) mice display impaired efferocytosis that could be repaired by IL- 4 through the expression of 12/15-LO and activation of PPAR- $\gamma$ (Fernandez-Boyanapalli et al., 2009). Hence, 15-LO-mediated signaling seems to be a major convergence point for efferocytosis and M2 polarization, and its down-stream signaling pathways could play a paramount role in deciphering whether macrophages will become pro-fibrotic or will finalize the resolution sequel to restore tissue homeostasis.

Along these reasoning, 12/15-LO products have been shown to be anti-inflammatory and to promote tissue repair, while playing an anti-fibrotic and immune-regulatory role (Serhan, 2010). The major bioactive 12/15-LO products could be produced from arachidonic acid to yield 15-HETE or lipoxins, or from DHA to generate protectin $\mathrm{D}$ (PD)1, resolvins of the $\mathrm{D}$ series, and the recently identified macrophage product maresin 1 (Serhan, 2010). While 15-HETE binds PPAR $\gamma$ to mediate its anti-inflammatory actions (Huang et al., 1999), $\mathrm{LXA}_{4}, \mathrm{PD} 1$, and resolvin D1 seem to act through binding to cell surface GPCRs (Serhan et al., 2011), as well as the aryl hydrocarbon receptor (that binds $\mathrm{LXA}_{4}$; Machado et al., 2006). All these 12/15-LO products induce a broad spectrum of anti-inflammatory actions on neutrophils and macrophages, as well as other cell types (Wittwer and Hersberger, 2007; Serhan et al., 2011). Lipoxins and PD1 are produced during epithelial injury in the cornea and mediate wound repair in addition to counteracting inflammation (Gronert et al., 2005). On the other hand, 12/15-LO products also induce unique pro-resolving properties of macrophages and promote regulatory pathways in lymphocytes. $\mathrm{LXA}_{4}, \mathrm{PD} 1, \mathrm{RvD} 1$, and PPAR $\gamma$ agonists were all found to promote efferocytosis and enhance PMN clearance during resolution (Godson et al., 2000; Schwab et al., 2007; Fernandez-Boyanapalli et al., 2009; Krishnamoorthy et al., 2010). In addition, PD1 and RvD1 were found to promote macrophage departure of resolving inflammation sites (Schwab et al., 2007; Schif-Zuck et al., 2011). $\mathrm{LXA}_{4}$ and PD1 inhibited inflammatory cytokine secretion from T lymphocytes (Ariel et al., 2003, 2005) and enhanced CCR5 expression on apoptotic PMN to promote clearance of its proinflammatory ligands (Ariel et al., 2006). Moreover, LXA 4 was recently found to play a role in the generation of myeloid-derived suppressor cells (Zhang et al., 2010). Of note, LXA 4 , PD1, and RvD1 are potent inhibitors of fibrosis in the lung and kidney (Duffield et al., 2006; Martins et al., 2009; Borgeson et al., 2011). Therefore, 15-LO products can be generated by macrophages following their interaction with apoptotic cells and/or polarization to the M2 phenotype. In turn, these products not only block inflammation but can also shift the macrophage healing balance from tissue repair/fibrosis to pro-resolution, anti-fibrotic, and regulatory functions. The exact mode of production and action for the different 15-LO products is probably dependent on substrate availability, concentration formed in the healing tissue and additional cues from the resolving environment. Nevertheless, they seem to act in concert to promote post-inflammation tissue healing and return to homeostasis.

\section{CD11B ${ }^{\text {LOW }}$ MACROPHAGES - A NEW PHENOTYPE GENERATED FOLLOWING SATIATED-EFFEROCYTOSIS}

Recent reports have indicated the co-existence of various macrophage phenotypes in resolving peritoneal cavities (Bystrom et al., 2008; Schif-Zuck et al., 2011). Macrophages from resolving murine peritonitis expressed an alternatively activated phenotype albeit with increase expression of M1 markers, such as cyclooxygenase 2 (COX 2) and iNOS (Bystrom et al., 2008). Thus, these macrophages were termed resolution-phase macrophages (rMs) and were postulated to have a hybrid phenotype of classically and alternatively activated macrophages (Bystrom et al., 2008). A recent report from the same group has indicated that rMs could be divided to at least three distinct populations based on F4/80 and Ly-6C expression, with varying expression of additional proinflammatory and anti-inflammatory markers as well as CD11b (Stables et al., 2011). Along these lines, we have recently characterized $\mathrm{F} 4 / 80^{+}$macrophages from resolving peritoneal exudates into two distinct macrophage subtypes: CD11 $\mathrm{b}^{\text {high }}$ and CD $11 \mathrm{~b}^{\text {low }}$ (Schif-Zuck et al., 2011). CD11b ${ }^{\text {high }}$ macrophages were found to express low to intermediate levels of the M1 markers iNOS, COX 2 , and matrix metalloproteinase (MMP)-9 and high levels of the M2 marker arginase-1. These cells also expressed very low levels of 12/15-LO. In addition, these macrophages secret medium levels of inflammatory cytokines and chemokines, as well as IL10 , in response to TLR ligands, are highly phagocytic, and do not migrate to lymphoid tissues. CD1 $1 b^{\text {low }}$ macrophages express even lower levels of iNOS, COX 2, and MMP-9 than CD $11 b^{\text {high }}$ ones, but they also do not express arginase- 1 . In addition, these macrophages secrete very low levels of inflammatory cytokines and chemokines, and IL-10, but higher amounts of TGF $\beta$. Moreover, CD11b macrophages, despite containing higher numbers of apoptotic $\mathrm{PMN}$, are no longer phagocytic and are prone to emigrate to remote sites. Hence, $\mathrm{CD} 11 \mathrm{~b}^{\text {low }}$ macrophages were termed "satiated" (Schif-Zuck et al., 2011). A seminal report from Ravichandran and colleagues (Park et al., 2011) has recently revealed that the mitochondrial membrane protein UCP2 controls satiation vs. continued clearance of apoptotic cells, and it would be interesting to examine its role in the generation of CD11b ${ }^{\text {low }}$ macrophages. The integration of the results from Schif-Zuck et al., Bystrom et al., and Stables et al. suggests $\mathrm{rM} / \mathrm{CD} 11 \mathrm{~b}^{\text {high }}$ macrophages are a mixed macrophage population with dominant M2-like characteristics, and some low-grade M1 activity and that early efferocytosis promotes the conversion of the M1-like population to an M2-like phenotype (Fadok et al., 1998; Freire-De-Lima et al., 2006; Korns et al., 2011) as well as enhanced phagocytosis/efferocytosis. However, the CD11b ${ }^{\text {low }}$ subset of macrophages, although converting from the $\mathrm{CD} 11 \mathrm{~b}^{\text {high }}$ subset ex vivo and in vivo (following late, threshold-meeting, efferocytosis; Schif-Zuck et al., 2011), are not M2-like, but rather display a distinct phenotype with its own molecular and functional characteristic (Figure 1). Of interest, a similar series of macrophage phenotype switches was found to take place 


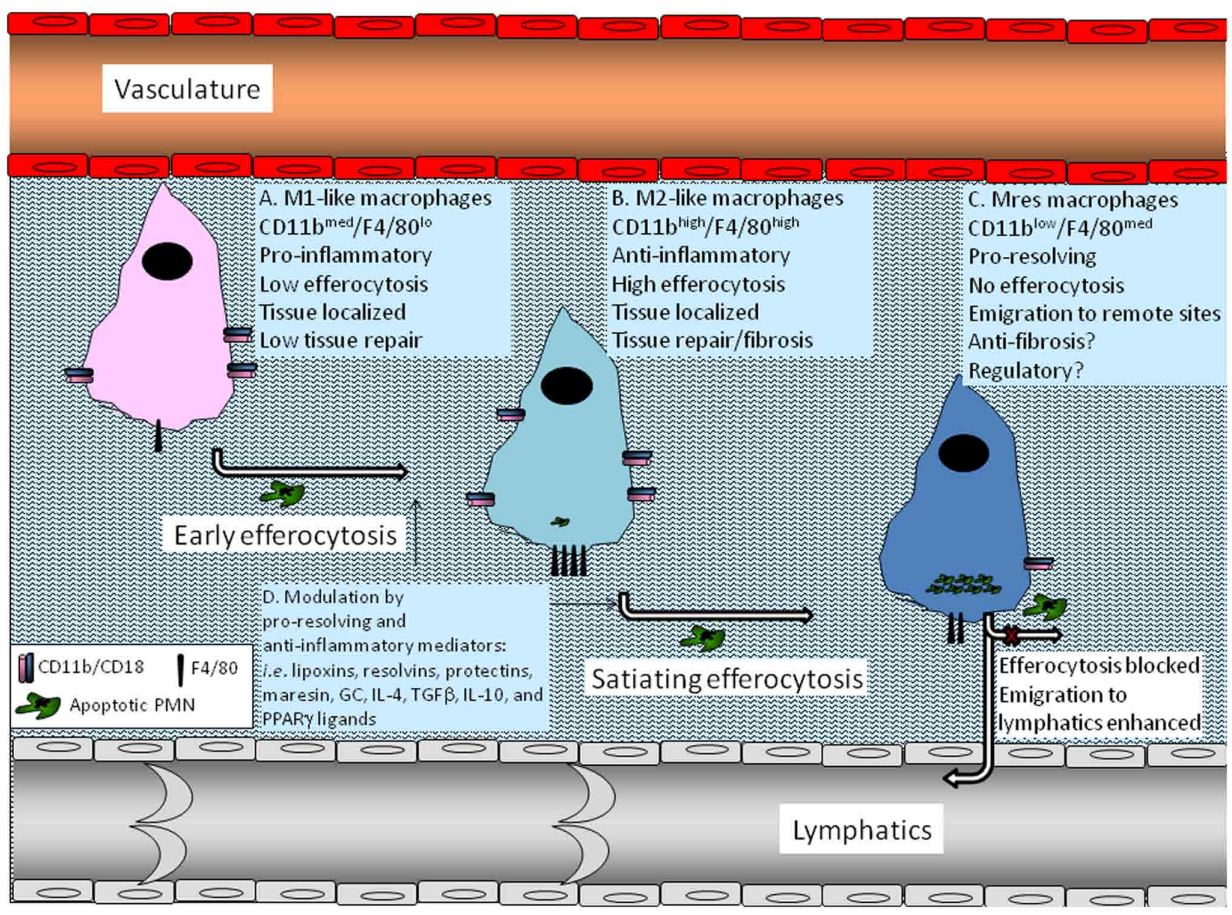

FIGURE 1 | Macrophage phenotype conversions induced by

efferocytosis. A monocyte that infiltrated an inflamed tissue differentiates to a macrophage and adopts an M1-like phenotype previous to encounter with apoptotic PMNs (A). Once it encounters apoptotic PMN and starts to engulf them (early efferocytosis), the macrophage switches to an M2-like phenotype that is anti-inflammatory, highly efferocytic, and involved in tissue repair and return to homeostasis, but can also promote fibrosis and scar formation (B) As the engulfment of apoptotic PMN by the macrophage continues and reaches a threshold level determined by the resolving milieu (satiating-efferocytosis) the macrophage undergoes another switch to the Mres phenotype (C). These macrophages reduce the expression of pro-fibrotic arginase-1 and display reduced phagocytosis of extracellular particle including apoptotic cells. Consequently, rapid Mres departure of the resolving tissue and emigration to remote sites takes place. At these target organs Mres macrophages presumably produce 12/15-LO-derived pro-resolving lipid mediators, and deliver homeostatic signals to antigen presenting cells and lymphocytes. Moreover, Mres that stay in the resolving tissue might express higher levels of anti-inflammatory, anti-fibrotic, and anti-oxidant proteins to limit tissue damage and fibrosis. 12/15-LO-derived lipid mediators probably also contribute to the anti-inflammatory and anti-fibrotic properties of Mres in the resolving tissue. Early and satiating-efferocytosis can be modulated by pro-resolving and anti-inflammatory mediators, such as lipoxins, resolvins, protectins, maresin, GC, IL-4, TGF $\beta$, IL-10, and PPAR $\gamma$ ligands (D). This modulation can enhance the immune-silencing and departure of Mres to the lymphatics, where they can contribute to the termination of acquired immune responses. during muscle injury and repair. These switches were induced by the engulfment of muscle debris that promoted TGF $\beta$ production and muscle regeneration (Arnold et al., 2007; Perdiguero et al., 2011). Importantly, the macrophage phenotype switch was mediated by a signaling cascade involving MAPK (Perdiguero et al., 2011) an essential module in macrophage inflammatory signaling (Kim et al., 2008).

Macrophages are important in limiting inflammation, excessive tissue repair, and fibrosis (Wynn and Barron, 2010). They also act at remote sites, such as lymphoid organs and adipose tissue (Schwab et al., 2007; Mukundan et al., 2009; Odegaard et al., 2007; Titos et al., 2011) to regulate acquired immune responses and metabolism. Since CD $11 b^{\text {low }}$ macrophages are distinct from either M1 or M2, do not express the pro-fibrotic enzyme arginase-1, stop phagocytosing foreign particles and can be found at lymphoid organs and adipose tissue (Schif-Zuck et al., 2011; Titos et al., 2011), we suggest these macrophages display a new phenotype, now termed resolution-promoting macrophages (Mres), which might be involved in anti-fibrotic, immune-regulatory, and metabolic processes, and hence is critical for the local and systemic termination of inflammatory episodes. The "decisionmaking" of macrophages on which phenotype will be expressed at a given time and setting is probably controlled by multiple variants in their milieu, including the number of apoptotic PMN they acquired and local concentrations of pro-resolving lipid mediators (from 15-LO and other pathways) and glucocorticoids (Schif-Zuck et al., 2011; Titos et al., 2011). Other macrophageinactivating and resolution-promoting cytokines, growth factors and lipid mediators, such as IL-10, TGF $\beta$, and PPAR $\gamma$ ligands are likely to also be important in regulating the fate of macrophages during the resolution of inflammation and the return of tissues to homeostasis.

\section{ACKNOWLEDGMENTS}

This work was supported by grants from the Israel Science Foundation (number 534/09), the Nutricia Research Foundationl, and the Marc Rich Foundation (to Amiram Ariel) and the National Institute of Health (R01 GM38765 and P01 GM095467 to Charles N. Serhan). Amiram Ariel is a recipient of the young scientist award from Teva Pharmaceuticals Ltd. 


\section{REFERENCES}

A-Gonzalez, N., Bensinger, S. J., Hong, C., Beceiro, S., Bradley, M. N., Zelcer, N., Deniz, J., Ramirez, C., Diaz, M., Gallardo, G., De Galarreta, C. R., Salazar, J., Lopez, F., Edwards, P., Parks, J., Andujar, M., Tontonoz, P., and Castrillo, A. (2009). Apoptotic cells promote their own clearance and immune tolerance through activation of the nuclear receptor LXR. Immunity 31, 245-258.

Ariel, A., Chiang, N., Arita, M., Petasis, N. A., and Serhan, C. N. (2003). Aspirin-triggered lipoxin A4 and B4 analogs block extracellular signal-regulated kinase-dependent TNF-alpha secretion from human $\mathrm{T}$ cells. J. Immunol. 170, 6266-6272.

Ariel, A., Fredman, G., Sun, Y. P., Kantarci, A., Van Dyke, T. E., Luster, A. D., and Serhan, C. N. (2006). Apoptotic neutrophils and $\mathrm{T}$ cells sequester chemokines during immune response resolution through modulation of CCR5 expression. Nat. Immunol. 7, 1209-1216.

Ariel, A., Li, P. L., Wang, W., Tang, W. X., Fredman, G., Hong, S., Gotlinger, K. H., and Serhan, C. N. (2005). The docosatriene protectin D1 is produced by $\mathrm{TH} 2$ skewing and promotes human $\mathrm{T}$ cell apoptosis via lipid raft clustering. J. Biol. Chem. 280, 43079-43086.

Arnold, L., Henry, A., Poron, F., BabaAmer, Y., Van Rooijen, N., Plonquet, A., Gherardi, R. K., and Chazaud, B. (2007). Inflammatory monocytes recruited after skeletal muscle injury switch into anti inflammatory macrophages to support myogenesis. J. Exp. Med. 204, 1057-1069.

Berry, A., Balard, P., Coste, A., Olagnier, D., Lagane, C., Authier, H., BenoitVical, F., Lepert, J. C., Seguela, J. P., Magnaval, J. F., Chambon, P., Metzger, D., Desvergne, B., Wahli, W., Auwerx, J., and Pipy, B. (2007). IL-13 induces expression of CD36 in human monocytes through PPARgamma activation. Eur. J. Immunol. 37, 1642-1652.

Borgeson, E., Docherty, N. G., Murphy, M., Rodgers, K., Ryan, A., O'sullivan, T. P., Guiry, P. J., Goldschmeding, R., Higgins, D. F., and Godson, C. (2011). Lipoxin A4 and benzo-lipoxin A4 attenuate experimental renal fibrosis. FASEB J. 25, 2967-2979.

Byrne, A., and Reen, D. J. (2002). Lipopolysaccharide induces rapid production of IL-10 by monocytes in the presence of apoptotic neutrophils. J. Immunol. 168, 1968-1977.

Bystrom, J., Evans, I., Newson, J., Stables, M., Toor, I., Van Rooijen, N., Crawford, M., Colville-Nash, P., Farrow, S., and Gilroy, D. W. (2008). Resolution-phase macrophages possess a unique inflammatory phenotype that is controlled by cAMP. Blood 112, 4117-4127.

Corne, J., Chupp, G., Lee, C. G., Homer, R. J., Zhu, Z., Chen, Q., Ma, B., Du, Y., Roux, F., Mcardle, J., Waxman, A. B. and Elias, J. A. (2000). IL-13 stimulates vascular endothelial cell growth factor and protects against hyperoxic acute lung injury. J. Clin. Invest. 106, 783-791.

Duffield, J. S., Hong, S., Vaidya, V. S., Lu, Y., Fredman, G., Serhan, C. N., and Bonventre, J. V. (2006). Resolvin D series and protectin D1 mitigate acute kidney injury. J. Immunol. 177, 5902-5911.

Erwig, L. P., and Henson, P. M. (2007). Immunological consequences of apoptotic cell phagocytosis. Am. J. Pathol. 171, 2-8.

Fadok, V. A., Bratton, D. L., Konowal, A., Freed, P. W., Westcott, J. Y., and Henson, P. M. (1998) Macrophages that have ingested apoptotic cells in vitro inhibit proinflammatory cytokine production through autocrine/paracrine mechanisms involving TGF-beta, PGE2, and PAF. J. Clin. Invest. 101, 890-898.

Fernandez-Boyanapalli, R. F., Frasch, S. C., Mcphillips, K., Vandivier, R. W., Harry, B. L., Riches, D. W., Henson, P. M., and Bratton, D. L. (2009). Impaired apoptotic cell clearance in CGD due to altered macrophage programming is reversed by phosphatidylserinedependent production of IL-4. Blood 113, 2047-2055.

Fichtner-Feigl, S., Strober, W., Kawakami, K., Puri, R. K., and Kitani, A. (2006). IL-13 signaling through the IL-13alpha2 receptor is involved in induction of TGF-betal production and fibrosis. Nat. Med. 12, 99-106.

Freire-De-Lima, C. G., Xiao, Y. Q., Gardai, S. J., Bratton, D. L., Schiemann, W. P., and Henson, P. M. (2006). Apoptotic cells, through transforming growth factor-beta, coordinately induce anti-inflammatory and suppress pro-inflammatory eicosanoid and NO synthesis in murine macrophages. J. Biol. Chem. 281, 38376-38384

Godson, C., Mitchell, S., Harvey, K., Petasis, N. A., Hogg, N., and Brady, H. R. (2000). Cutting edge: lipoxins rapidly stimulate nonphlogistic phagocytosis of apoptotic neutrophils by monocytederived macrophages. J. Immunol. 164, 1663-1667.

Golpon, H. A., Fadok, V. A. Taraseviciene-Stewart, L., Scerbavicius, R., Sauer, C., Welte, T. Henson, P. M., and Voelkel, N. F. (2004). Life after corpse engulfment: phagocytosis of apoptotic cells leads to VEGF secretion and cell growth. FASEB J. 18, 1716-1718.

Gronert, K., Maheshwari, N., Khan, N., Hassan, I. R., Dunn, M., and Laniado Schwartzman, M. (2005). A role for the mouse 12/15lipoxygenase pathway in promoting epithelial wound healing and host defense. J. Biol. Chem. 280, 15267-15278.

Hesse, M., Modolell, M., La Flamme, A. C., Schito, M., Fuentes, J. M., Cheever, A. W., Pearce, E. J., and Wynn, T. A. (2001). Differential regulation of nitric oxide synthase-2 and arginase- 1 by type $1 /$ type 2 cytokines in vivo: granulomatous pathology is shaped by the pattern of L-arginine metabolism. J. Immunol. 167, 6533-6544.

Heydeck, D., Thomas, L., Schnurr, K., Trebus, F., Thierfelder, W. E. Ihle, J. N., and Kuhn, H. (1998). Interleukin-4 and -13 induce upregulation of the murine macrophage 12/15-lipoxygenase activity: evidence for the involvement of transcription factor STAT6. Blood 92, 2503-2510.

Huang, J. T., Welch, J. S., Ricote, M., Binder, C. J., Willson, T. M. Kelly, C., Witztum, J. L., Funk, C. D., Conrad, D., and Glass, C. K. (1999). Interleukin-4-dependent production of PPAR-gamma ligands in macrophages by $12 / 15$ lipoxygenase. Nature 400, 378-382.

Huynh, M. L., Fadok, V. A., and Henson, P. M. (2002). Phosphatidylserinedependent ingestion of apoptotic cells promotes TGF-betal secretion and the resolution of inflammation. J. Clin. Invest. 109, 41-50.

Johann, A. M., Von Knethen, A., Lindemann, D., and Brune, B. (2006). Recognition of apoptotic cells by macrophages activates the peroxisome proliferator-activated receptor-gamma and attenuates the oxidative burst. Cell Death Differ. 13, 1533-1540.

Kang, K., Reilly, S. M., Karabacak, V., Gangl, M. R., Fitzgerald, K., Hatano, B., and Lee, C. H. (2008). Adipocyte-derived Th2 cytokines and myeloid PPARdelta regulate macrophage polarization and insulin sensitivity. Cell Metab. 7 485-495.

Kim, C., Sano, Y., Todorova, K., Carlson, B. A., Arpa, L., Celada, A., Lawrence, T., Otsu, K., Brissette, J. L., Arthur, J. S., and Park, J. M. (2008). The kinase p38 alpha serves cell typespecific inflammatory functions in skin injury and coordinates pro- and anti-inflammatory gene expression. Nat. Immunol. 9, 1019-1027.

Kim, S., Elkon, K. B., and Ma, X (2004). Transcriptional suppression of interleukin-12 gene expression following phagocytosis of apoptotic cells. Immunity 21, 643-653.

Korns, D., Frasch, S. C., FernandezBoyanapalli, R., Henson, P. M., and Bratton, D. L. (2011). Modulation of macrophage efferocytosis in inflammation. Front. Immun. 2:57. doi: 10.3389/fimmu.2011.00057

Krishnamoorthy, S., Recchiuti, A., Chiang, N., Yacoubian, S., Lee, C. H., Yang, R., Petasis, N. A., and Serhan, C. N. (2010). Resolvin D1 binds human phagocytes with evidence for proresolving receptors. Proc. Natl. Acad. Sci. U.S.A. 107, 1660-1665.

Levy, B. D., Romano, M., Chapman, H. A., Reilly, J. J., Drazen, J., and Serhan, C. N. (1993). Human alveolar macrophages have 15-lipoxygenase and generate 15(S)-hydroxy-5,8,11cis-13-trans-eicosatetraenoic acid and lipoxins. J. Clin. Invest. 92, 1572-1579.

Machado, F. S., Johndrow, J. E., Esper, L., Dias, A., Bafica, A., Serhan, C. N., and Aliberti, J. (2006). Antiinflammatory actions of lipoxin A4 and aspirin-triggered lipoxin are SOCS-2 dependent. Nat. Med. 12, 330-334.

Maddox, J. F., Colgan, S. P., Clish, C. B., Petasis, N. A., Fokin, V. V., and Serhan, C. N. (1998). Lipoxin B4 regulates human monocyte/neutrophil adherence and motility: design of stable lipoxin B4 analogs with increased biologic activity. FASEB J. 12, 487-494.

Maddox, J. F., Hachicha, M., Takano, T., Petasis, N. A., Fokin, V. V., and Serhan, C. N. (1997). Lipoxin A4 stable analogs are potent mimetics that stimulate human monocytes and THP-1 cells via a G-proteinlinked lipoxin A4 receptor. J. Biol. Chem. 272, 6972-6978.

Maddox, J. F., and Serhan, C. N. (1996). Lipoxin A4 and B4 are potent stimuli for human monocyte migration and adhesion: selective inactivation by dehydrogenation and reduction. J. Exp. Med. 183, 137-146. 
Mantovani, A., Sica, A., and Locati, M. (2005). Macrophage polarization comes of age. Immunity 23, 344-346.

Mantovani, A., Sica, A., Sozzani, S., Allavena, P., Vecchi, A., and Locati, M. (2004). The chemokine system in diverse forms of macrophage activation and polarization. Trends Immunol. 25, 677-686.

Martinez, F. O., Helming, L., and Gordon, S. (2009). Alternative activation of macrophages: an immunologic functional perspective. Annu. Rev. Immunol. 27, 451-483.

Martinez, F. O., Sica, A., Mantovani, A., and Locati, M. (2008). Macrophage activation and polarization. Front. Biosci. 13, 453-461.

Martins, V., Valenca, S. S., Farias-Filho, F. A., Molinaro, R., Simoes, R. L., Ferreira, T. P., E Silva, P. M., Hogaboam, C. M., Kunkel, S. L., Fierro, I. M., Canetti, C., and Benjamim, C. F. (2009). ATLa, an aspirin-triggered lipoxin A4 synthetic analog, prevents the inflammatory and fibrotic effects of bleomycin-induced pulmonary fibrosis. J. Immunol. 182, 5374-5381.

Merched, A. J., Ko, K., Gotlinger, K. H., Serhan, C. N., and Chan, L. (2008). Atherosclerosis: evidence for impairment of resolution of vascular inflammation governed by specific lipid mediators. FASEB J. 22, 3595-3606.

Mitchell, S., Thomas, G., Harvey, K., Cottell, D., Reville, K., Berlasconi, G., Petasis, N. A., Erwig, L., Rees, A. J., Savill, J., Brady, H. R., and Godson, C. (2002). Lipoxins, aspirintriggered epi-lipoxins, lipoxin stable analogues, and the resolution of inflammation: stimulation of macrophage phagocytosis of apoptotic neutrophils in vivo. J. Am. Soc. Nephrol. 13, 2497-2507.

Mukundan, L., Odegaard, J. I., Morel, C. R., Heredia, J. E., Mwangi, J. W., Ricardo-Gonzalez, R. R., Goh, Y. P., Eagle, A. R., Dunn, S. E., Awakuni, J. U., Nguyen, K. D., Steinman, L., Michie, S. A., and Chawla, A. (2009). PPAR-delta senses and orchestrates clearance of apoptotic cells to promote tolerance. Nat. Med. 15, 1266-1272.

Nassar, G. M., Morrow, J. D., Roberts, L. N., Lakkis, F. G., and Badr, K. F. (1994). Induction of 15lipoxygenase by interleukin-13 in human blood monocytes. J. Biol. Chem. 269, 27631-27634.

Nathan, C. F., Murray, H. W., Wiebe, M. E., and Rubin, B. Y. (1983). Identification of interferon-gamma as the lymphokine that activates human macrophage oxidative metabolism and antimicrobial activity. J. Exp. Med. 158, 670-689.

Odegaard, J. I., Ricardo-Gonzalez, R. R., Goforth, M. H., Morel, C. R., Subramanian, V., Mukundan, L., Red Eagle, A., Vats, D., Brombacher, F., Ferrante, A. W., and Chawla, A. (2007). Macrophage-specific PPARgamma controls alternative activation and improves insulin resistance. Nature 447, 1116-1120.

Park, D., Han, C. Z., Elliott, M. R., Kinchen, J. M., Trampont, P. C., Das, S., Collins, S., Lysiak, J. J., Hoehn, K. L., and Ravichandran, K. S. (2011). Continued clearance of apoptotic cells critically depends on the phagocyte Ucp2 protein. Nature 477, 220-224.

Patel, V. A., Longacre, A., Hsiao, K., Fan, H., Meng, F., Mitchell, J. E., Rauch, J., Ucker, D. S., and Levine, J. S. (2006). Apoptotic cells, at all stages of the death process, trigger characteristic signaling events that are divergent from and dominant over those triggered by necrotic cells: implications for the delayed clearance model of autoimmunity. J. Biol. Chem. 281, 4663-4670.

Perdiguero, E., Sousa-Victor, P., RuizBonilla, V., Jardi, M., Caelles, C., Serrano, A. L., and Munoz-Canoves, P. (2011). p38/MKP-1-regulated AKT coordinates macrophage transitions and resolution of inflammation during tissue repair. J. Cell Biol. 195, 307-322.

Pourcet, B., Feig, J. E., Vengrenyuk, Y., Hobbs, A., Kepka-Lenhart, D., Garabedian, M., Morris, S. M. Jr., Fisher, E. A., and PinedaTorra, I. (2011). LXR \{alpha\} regulates macrophage arginase 1 through PU.1 and interferon regulatory factor 8. Circ. Res. 109, 492-501.

Raes, G., DE Baetselier, P., Noel, W., Beschin, A., Brombacher, F., and Hassanzadeh GH, G. (2002). Differential expression of FIZZ1 and Ym1 in alternatively versus classically activated macrophages. J. Leukoc. Biol. 71, 597-602.

Raes, G., Van Den Bergh, R., DE Baetselier, P., Ghassabeh, G. H., Scotton,
C., Locati, M., Mantovani, A., and Sozzani, S. (2005). Arginase-1 and Yml are markers for murine, but not human, alternatively activated myeloid cells. J. Immunol. 174, 6561; author reply 6561-6562.

Ravichandran, K. S. (2011). Beginnings of a good apoptotic meal: the findme and eat-me signaling pathways. Immunity 35, 445-455.

Ravichandran, K. S., and Lorenz, U. (2007). Engulfment of apoptotic cells: signals for a good meal. Nat Rev. Immunol. 7, 964-974.

Savill, J., Dransfield, I., Gregory, C., and Haslett, C. (2002). A blast from the past: clearance of apoptotic cells regulates immune responses. Nat. Rev. Immunol. 2, 965-975.

Schif-Zuck, S., Gross, N., Assi, S., Rostoker, R., Serhan, C. N., and Ariel, A. (2011). Saturated-efferocytosis generates pro-resolving CD11b (low) macrophages: modulation by resolvins and glucocorticoids. Eur. J. Immunol. 41, 366-379.

Schwab, J. M., Chiang, N., Arita M., and Serhan, C. N. (2007). Resolvin E1 and protectin D1 activate inflammation-resolution programmes. Nature 447, 869-874.

Serhan, C. N. (2010). Novel lipid mediators and resolution mechanisms in acute inflammation: to resolve or not? Am. J. Pathol. 177, 1576-1591.

Serhan, C. N., Krishnamoorthy, S., Recchiuti, A., and Chiang, N. (2011). Novel anti-inflammatory - proresolving mediators and their receptors. Curr. Top. Med. Chem. 11, 629-647.

Serhan, C. N., Yang, R., Martinod, K., Kasuga, K., Pillai, P. S., Porter, T. F., Oh, S. F., and Spite, M. (2009). Maresins: novel macrophage mediators with potent antiinflammatory and proresolving actions. J. Exp. Med. 206, 15-23.

Stables, M. J., Shah, S., Camon, E. B., Lovering, R. C., Newson, J., Bystrom, J., Farrow, S. and Gilroy, D. W. (2011). Transcriptomic analyses of murine resolution-phase macrophages. Blood 118, e192-e208.

Titos, E., Rius, B., Gonzalez-Periz, A. Lopez-Vicario, C., Moran-Salvador, E., Martinez-Clemente, M., Arroyo, V., and Claria, J. (2011). Resolvin D1 and its precursor docosahexaenoic acid promote resolution of adipose tissue inflammation by eliciting macrophage polarization toward an
M2-like phenotype. J. Immunol. 187, 5408-5418.

Voll, R. E., Herrmann, M., Roth, E. A., Stach, C., Kalden, J. R., and Girkontaite, I. (1997). Immunosuppressive effects of apoptotic cells. Nature 390, 350-351.

Wittwer, J., and Hersberger, M. (2007). The two faces of the 15-lipoxygenase in atherosclerosis. Prostaglandins Leukot. Essent. Fatty Acids 77, 67-77.

Wynn, T. A. (2008). Cellular and molecular mechanisms of fibrosis. J. Pathol. 214, 199-210.

Wynn, T. A., and Barron, L. (2010). Macrophages: master regulators of inflammation and fibrosis. Semin. Liver Dis. 30, 245-257.

Zhang, B., Jia, H., Liu, J., Yang, Z., Jiang, T., Tang, K., Li, D., Huang, C., Ma, J., Shen, G. X., Ye, D., and Huang, B. (2010). Depletion of regulatory $\mathrm{T}$ cells facilitates growth of established tumors: a mechanism involving the regulation of myeloid-derived suppressor cells by lipoxin A4. J. Immunol. 185, 7199-7206.

Conflict of Interest Statement: Charles $\mathrm{N}$. Serhan is an inventor on patents (resolvins) assigned to BWH and licensed to Resolvyx Pharmaceuticals. Charles N. Serhan is a scientific founder of Resolvyx Pharmaceuticals and owns equity in the company. Charles N. Serhan' interests were reviewed and are managed by the Brigham and Women's Hospital and Partners HealthCare in accordance with their conflict of interest policies.

Received: 29 August 2011; accepted: 07 January 2012; published online: 31 January 2012.

Citation: Ariel A and Serhan CN (2012) New lives given by cell death: macrophage differentiation following their encounter with apoptotic leukocytes during the resolution of inflammation. Front. Immun. 3:4. doi: 10.3389/fimmu.2012.00004

This article was submitted to Frontiers in Inflammation, a specialty of Frontiers in Immunology.

Copyright (C) 2012 Ariel and Serhan. This is an open-access article distributed under the terms of the Creative Commons Attribution Non Commercial License, which permits non-commercial use, distribution, and reproduction in other forums, provided the original authors and source are credited. 